\title{
ESTIMATING EXTREME DRY-SPELL RISK IN THE MIDDLE EBRO VALLEY (NE SPAIN): A COMPARATIVE ANALYSIS OF PARTIAL DURATION SERIES WITH A GENERAL PARETO DISTRIBUTION AND ANNUAL MAXIMA SERIES WITH A GUMBEL DISTRIBUTION
}

\author{
S.M. VICENTE-SERRANO ${ }^{a *}$ and S. BEGUERÍA-PORTUGUÉS ${ }^{\mathrm{b}}$ \\ a Departamento de Geografía. Universidad de Zaragoza. Campus de San Francisco, 50009- \\ Zaragoza. Spain. \\ ${ }^{\mathrm{b}}$ Instituto Pirenaico de Ecología (CSIC). Campus de Aula Dei. Apdo. 202. 50080- \\ Zaragoza. Spain. \\ * Correspondence to Sergio M. Vicente-Serrano, Departamento de Geografía. Universidad \\ de Zaragoza. Campus de San Francisco, 50009-Zaragoza. Spain. \\ e-mail: svicen@posta.unizar.es
}

\begin{abstract}
This paper analyses fifty-year time series of daily precipitation in a region of the middle Ebro valley (northern Spain) in order to predict extreme dry-spell risk. A comparison of observed and estimated maximum dry spells (50-year return period) showed that the Generalised Pareto (GP) distribution combined with partial duration series (PDS) gives better results than the Gumbel distribution fitted to annual maximum series (AMS). Indeed, the classical Gumbel approach underestimated the empirical duration of dry spells. The PDS/GP approach was successfully applied in the study of extreme hydro-climatic variable values. The results reported here could be applied in estimating climatic drought risks in other geographical areas.
\end{abstract}

Keywords: Dry spells, return periods, drought, partial duration series, annual maximum series, Gumbel distribution, Generalized Pareto distribution, Ebro valley, Spain. 


\section{1- INTRODUCTION}

There is great interest in determining the return periods of extreme hydrological events (precipitation or flows) so as to mitigate possible associated risks and considerable efforts have been made to develop stochastic methods to determine such risks accurately (WMO, 1989; Bobée and Rasmussen, 1995). The results of these probabilistic analyses are essential information in a range of activities including the construction of infrastructures, the expansion of population centres and land-use management .

Of all twentieth century natural hazards, droughts are those that have had the greatest detrimental impact (Obasi, 1994; Bruce, 1994). But droughts are not easily defined and need to be understood in terms of their hydrological, agricultural, and socio-economic impact (Dracup et al., 1980; Wilhite and Glantz, 1985). Although the causes of drought can be multiple (involving both human and physical factors), the on-set of a drought is usually caused by the decrease in, or absence of, precipitation.

Droughts cause major economic and human losses, affecting hundreds of millions of people, and numerous studies have highlighted the need for drought prevention and mitigation plans (Wilhite, 1991 and 1996; Wilhite and Wood, 1985; Wilhite et al., 1986; Sangoyomi and Harding, 1995). In order to protect agriculture and other socio-economic concerns the spatial and temporal assessment of droughts is necessary, while areas at risk from droughts of long duration and great intensity need to be determined. Sivakumar (1992) stresses the importance of recognising spatial patterns of extreme drought, which can then be used in the management of cultivated areas (crop selection, irrigation planning, etc.). 
The study of hydrological extremes has typically focused on clearly defined episodes (principally floods), while other equally major but more gradual risks such as droughts the on-set and termination of which are often unclear (Wilhite and Glantz, 1985) - have received less attention. Even less attention has been paid to the development of methods for studying extreme drought risk. And, although the consequences of a drought are more difficult to identify than those of an instantaneous risk, they can often be much worse. For this reason, advances in the development of methods that allow us to estimate more accurately the risk of occurrence are essential. Furthermore, the close links between crop types and agricultural productions and climatic characteristics mean the methods for estimating drought risk in agrarian planning are vital.

Many approaches have been adopted in the analysis of climatic droughts. Several studies have analysed droughts using monthly precipitation data, where droughts are considered as precipitation deficits with respect to average values (Gibbs, 1975). Recently, this approach has been improved, and better indices have been developed for a range of time scales (McKee et al., 1993 and 1995; Hayes et al., 1999). Some studies have looked at various factors in addition to precipitation, considering droughts as shortages in the soil water balance (Thornthwaite, 1948; Palmer, 1965). Other approaches analyse drought duration and intensity in relation to cumulative precipitation shortages (Chang and Kleopa, 1991; Estrela et al., 2000) .

The utility of these drought indices is greater in drought monitoring and management since they enable drought intensity, duration and magnitude to be identified, and the drought intensity in a number of areas to be compared at the same point in time. Yet, these indices are not so useful for identifying spatial patterns of drought risk, as they are based on 
standardized or normalized shortages in relation to average conditions. Thus, even when the duration of the drought index series is long, the drought index values will occur with the same frequency (Lana et al., 2001).

Sequences of days without precipitation, or dry spells, have frequently been used in the spatial analysis of drought risk. Drought duration and intensity are directly proportional to the number of days without precipitation (Dracup et al., 1980). Several statistical methods have been used to determine the drought risk based on dry spells in the daily precipitation series. These include the Markov chain series (Lana and Burgueño, 1998a; Martín-Vide et al., 1992; Pérez-Manrique et al., 1984; Martín-Vide and Gómez, 1999) and different probability distributions, e.g., the exponential (Davy, 1978; Creus et al., 1981), the Eggenberger-Polya (Berger and Goosenes, 1983), and the truncated negative binomial (De Arruda and Pinto, 1980; Nobilis, 1986; Douguedroit, 1987 and 1990). These distributions are adjusted empirically to the original data series, and the return periods of dry spells of given duration are estimated. However, these distributions do not exhibit good fit to the extremes of the dry-spell series (Gabriel and Neumann, 1957; Flannigan and Harrington, 1988; Perzyna, 1994). As the time between events increases, their stochastic dependence falls, so that the most extreme dry spells in the series can be considered a random variable. The difficulties encountered in estimating the probability of occurrence of extreme dry spells is unfortunate because a better understanding of these phenomena might mean that the highly detrimental effects on the environment, water resources, and agriculture could be avoided.

Traditionally, the analysis of extremes in dry-spell series has been examined using annual maximum series (AMS) adjusted to a Gumbel distribution (Gupta and Duckstein, 1975; 
Lana and Burgueño, 1998b; Ascaso and Casals, 1981). The AMS are constructed by determining the maximum dry spell for each year, so the series length equals the number of years for which records are available. However, this approach is not free of problems. The main drawback is the loss of the $2^{\text {nd }}, 3^{\text {rd }}$, etc, largest annual dry spells, which might be considered extreme dry spells, and which might exceed the maximum dry spells of other years. An alternative approach is the partial duration series (PDS), which are constructed using the values above a selected threshold regardless of the year in which they occurred (Hershfield, 1973). Typically, the Generalized Pareto (GP) distribution has been used to model PDS (Bobée and Rassmussen, 1995). Although the PDS approach has obvious advantages over the AMS approach (Cunnane, 1973), it has been used only infrequently in precipitation dry-spell analysis (see, e. g., ARIDE, 2002).

The objectives of this paper are three: First, to determine whether the use of AMS with the Gumbel distribution (AMS/G approach) is suitable for modelling extreme daily dry-spell risk; second, to analyse if PDS with the Generalized Pareto (PDS/GP) is adequate for modelling extreme dry-spell risk; third, to compare both approaches with the observed maximum dry spells to determine the most suitable estimation of drought risk.

The data series studied correspond to the middle Ebro valley (North-East Spain). Fortythree daily precipitation series from 1951 to 2000 were used. In this area, the low annual precipitation and the frequent long dry spells are a major restrictive factor in crop growth. For this reason, this area is particularly suitable for testing these methods. 


\section{1- STUDY AREA}

The location of the study area is shown in Figure 1. It is a heavily settled area with scant vegetation. The relief isolates the valley, largely impeding any maritime influences and giving it a continental climate. These features similarly determine the complexity of its climate, its principal feature being its aridity (Cuadrat, 1991; Creus and Ferraz, 1995; Creus 1996). The proximity of the Mediterranean sea, however, and the location of the study area in a climatic transition area (Balairón, 1997) give rise to significant temporal variability, alternating years of high precipitation associated with the polar fronts with years dominated by Mediterranean disturbances (Creus, 1983).

The annual precipitation oscillates between 300 and $450 \mathrm{~mm}$ in the valley bottom, and more than $800 \mathrm{~mm}$ in the northern and southern mountain areas (Figure 2). A high interannual variability is observed as a consequence of the alternation of dominant atmospheric patterns. There are years in which the precipitation greatly exceeds the mean value; in other years, the values are less than a third of the mean, and long drought periods are then particularly frequent (Saz and Creus, 1998; Cuadrat et al., 2002). The mean annual temperatures oscillate between 14 and $16^{\circ} \mathrm{C}$ in the valley bottom, and below $11^{\circ} \mathrm{C}$ in the highest sectors.

The spatial distribution of the annual percentage of dry days is shown in Figure 3. Two thresholds are considered: $0.1 \mathrm{~mm}$ and $5 \mathrm{~mm}$. In the case of the $0.1 \mathrm{~mm}$ threshold, a NWSE gradation exists. In the north-west, just less than $80 \%$ of the days are dry, with a progressive increment in this value towards the east, with more than $88 \%$ of the days recording precipitation at or below the threshold. At the $5 \mathrm{~mm}$ threshold, there is a N-S gradient with the largest percentage of dry days being recorded in the central valley ( $>93$ 
\%). The lowest values appear in the north $(<88 \%)$, whereas in the southern ranges a secondary minimum is reached where the influence of Mediterranean disturbances coincides with higher relief features.

\section{2- METHODOLOGY}

\section{1- Data base elaboration}

Of the 380 weather stations in the central Ebro valley, we selected those for which less than $15 \%$ of values were missing for the period 1951-2000. This gave a total of 43 observatories (Figure 1). The weather stations were homogeneously distributed, although the density in the western and south-western sectors was lower.

Using data from neighbouring stations, Romero et al. (1998) outlined a method for completing daily precipitation series. In the observatories of the Ebro valley, the missing values were substituted by means of the weighted average of the daily precipitation of the stations located within a 15-kilometre radius of the candidate station:

$$
P_{i}=\frac{\sum_{j=1}^{n} P_{j} d_{i j}}{\sum_{j=1}^{n} d_{i j}}
$$

where $P_{i}$ is the precipitation at the candidate observatory, $P_{j}$ is the precipitation at the neighbouring observatory and $d_{i j}$ (the distance between points $i$ and $j$ ) is the weighting factor. For the 43 weather stations, dry-spell series were obtained for two distinct thresholds. The dry-spell term refers to series of consecutive days with precipitation less than or equal to a given threshold ( $\leq \alpha \mathrm{mm}$, Douguedroit, 1987; Nobilis, 1986; Ascaso and 
Casals, 1981). Commonly, a threshold of $0.1 \mathrm{~mm}$ is applied (Lana and Burgueño, 1998a; Martin-Vide and Gómez, 1999; Pérez Manrique et al., 1984), though a number of authors have used other thresholds. Hershfield (1981) used a $1 \mathrm{~mm}$ threshold in the analysis of the frequency of dry days in the USA. Harrington and Flannigan (1993) used a $1.5 \mathrm{~mm}$ threshold; given, they claim, that in forested areas the first $1.5 \mathrm{~mm}$ are intercepted by trees. Douguedroit (1987) considered a $1 \mathrm{~mm}$ threshold in Mediterranean climatic environments, since below that quantity the precipitation is not absorbed by soils in conditions of high evapotranspiration. The same threshold was used by Galliani and Filippini (1985) in the east of Italy. Martin-Vide and Gómez (1999) used a threshold of $10 \mathrm{~mm}$. With this threshold, isolated days with low precipitation can be eliminated because these days can conclude a long dry-spell when defining the events, even when the drought has not ended. Sivakumar (1992), in an analysis of dry-spell frequency in Niger, established a range of thresholds from 1 to $25 \mathrm{~mm}$. Perzyna (1994) used a $2 \mathrm{~mm}$ threshold in Norway. Finally, Alyamani and Sen (1997) used a 0 mm threshold in dry-spell analysis in Saudi Arabia.

Here, two thresholds were used: $0.1 \mathrm{~mm}$ and $5 \mathrm{~mm}$, the former representing the minimum quantity of precipitation that the official pluviometer in Spain records. Higher thresholds were not considered, since in this semi-arid region the natural vegetation and cultivations are adapted to the climatic conditions. Thus, during drought periods, one isolated precipitation of more than $5 \mathrm{~mm}$ can allow vegetation growth provided that it takes place at the opportune moment (Austin et al., 1998).

\section{2. - Extreme dry-spell modelling with annual maximum series and Gumbel distribution.}


The most commonly used distribution for extreme dry-spell frequency modelling is the AMS/G approach (Gumbel, 1958; Lana and Burgueño, 1998b; Ascaso and Casals, 1981; Perzyna, 1994). The Gumbel distribution is a two-parameter distribution with constant skewness. It is a particular case of the three-parameter Generalised Extreme Value distribution (GEV), that is the limit distribution for maxima series. The Gumbel is usually preferred to the GEV because of its ease of calculation. Its probability density function is:

$f(x)=\frac{1}{\alpha} e^{-\left(\frac{x-\beta}{\alpha}\right)^{-e^{-\left(\frac{x-\beta}{a}\right)}}}$

and its cumulative distribution function is expressed:

$F(x)=e^{-e^{-\left(\frac{x-\beta}{\alpha}\right)}}$

where $x$ is the value of the variable, $\alpha$ and $\beta$ are the parameters of the distribution. They are commonly estimated by the method of moments (Chow, 1964; Rao and Hamed, 2000), although they can also be estimated by L-moments (Greenwood et al., 1979). The method of L-moments was preferred here because it yields more robust estimations than conventional moments (Sankarasubramanian and Srinivasan, 1999; Vogel and Fennessey, 1993). Hosking (1990) explains in detail the estimation of parameters using L-moments.

The prospective maximum dry-spell for a $T$ year period $X_{T}$, can be calculated using:

$X_{T}=\beta-\alpha \ln [-\ln (1-(1 / T)]$

\section{3. - Estimation of extreme dry spells using partial duration series (PDS)}

\subsection{1- Characteristics of partial duration series}


Although the preceding method has been widely used in the study of extreme dry spells, in the analysis of other hydrological and climatic variables (e.g. extreme rainfall, floods) many studies prefer to use PDS or series of peaks over an upper limit. Given the dry spell series $x=\left\{x_{1}, x_{2}, \ldots, x_{i}\right\}$, for the station $x$, where $x_{n}$ is the duration of a given dry spell, the PDS $y=\left\{y_{1}, y_{2}, \ldots, y_{j}\right\}$ consists of all the values of the original series that exceed a predetermined upper limit, $x_{0}$ :

$y_{j}=x_{i}-x_{0} \quad \forall \quad x_{i}>x_{0}$

The size of the series obtained depends, therefore, on the upper limit, $x_{0}$. For this reason, PDS use the information contained in the original sample more efficiently, and permit the inclusion of more than one event per year, if they satisfy the conditions established in defining an extreme event (Kite, 1977; Chow et al., 1988).

\subsection{2- Probability distributions used to adjust partial duration series}

Many probability distributions have been adjusted to PDS hydrological series, including lognormal, Pearson III, Gamma, General Extreme Value, Wakeby, Weibull, etc. (Bobee et al., 1993; Rao and Hamed, 2000). Many recent studies have demonstrated the better performance of the Generalized Pareto (GP) distribution in the fit of extreme hydrological variables using PDS (Madsen et al., 1997a and b). The GP is the limit distribution for excess over a lower bound series as is the General Extreme Value in the case of the AMS series.

The GP distribution function is:

$F(x)=1-\left[1-\frac{\kappa}{\alpha}(x-\varepsilon)\right]^{1 / x}$ 
where $\kappa$ is the shape parameter and $\alpha$ is the scale parameter of the distribution, $\varepsilon$ is the location parameter or distribution origin that corresponds to the lower bound of the PDS, $x_{0}$. The parameters of the distribution can be obtained by L-moments (Hosking, 1990):

$$
\begin{aligned}
& \alpha=\lambda_{1}\left(\frac{1}{\tau_{2}}-1\right) \\
& \kappa=\frac{1}{\tau_{2}}-2
\end{aligned}
$$

The event $X_{T}$ in a period of $T$ years is obtained using:

$$
X_{T}=\varepsilon+\frac{\alpha}{\kappa}\left[1-\left(\frac{1}{\lambda T}\right)^{\kappa}\right]
$$

where $\lambda$ is the average number of events per year above the upper limit.

Hosking (1990) gives parametric approximations to the relationships between $\tau_{3}$ and $\tau_{4}$ (Lskewness, and L-kurtosis, respectively), which permit comparison with the ratio estimations, and determine the suitability of the proposed distribution.

A major problem in using PDS is the selection of the lower bound, $x_{0}$. This value should be low enough to ensure the inclusion of as much relevant information as possible, without violating the assumption of independence of the peaks. Various methods have been proposed to determine the most appropriate lower bound (Ashkar and Rouselle, 1987; Madsen et al., 1997a). However, Beguería (2003) has shown that the parameters and quantile estimations vary randomly with the threshold value, and no single value is entirely adequate. For this reason, in this paper the maximum dry spell in the 50 -year period was calculated using different lower bounds in the PDS/GP approach. These bounds were 
defined using the percentiles of the dry-spell series every 0.25 from the 90 to 99.75 percentiles. Dry spells were considered extreme above the 90 percentile.

\section{4- Comparison of the AMS/G and PDS/GP series approaches}

The maximum dry spell observed in each series in the period 1951-2000 was extracted. These were compared with the 50-year estimates using the AMS/G and PDS/GP approaches. It is clear that the maximum dry spell observed in a 50-year period does not necessarily correspond to a return period of 50 years. This limitation was partially overcome by using several weather stations in the same region. The goodness of fit was tested by means of the root mean square error (RMSE, Willmot, 1982), the lowest value indicating the best estimation.

$$
R M S E=\sqrt{\frac{1}{n} \sum_{i=1}^{n}\left(z_{i}-z_{i}\right)^{2}}
$$

$z_{i}$ is the observed value and the circumflex ${ }^{\wedge}$ indicates estimation using annual maximum or partial duration series; $n$ is the number of weather stations.

\section{3- RESULTS}

\section{1- Performance of the AMS/G and PDS/GP approaches}

In Figure 4, the L-moment ratios diagram is shown. The theoretical curve of GP distribution is shown along with the PDS ratios obtained using three different lower bounds (defined by percentiles 90, 95 and 97) using the dry-spell series defined at $0.1 \mathrm{~mm}$. The Gumbel distribution ratios are also shown as a point, along with the data from the AMS. Figure 5 shows the same data, for the series of dry spells defined at $5 \mathrm{~mm}$. The goodness of 
fit of the PDS clouds was higher for the lowest lower bound (percentile 90) and for the 0.1 $\mathrm{mm}$ dry-spell series. Both effects were due to the reduction in the number of events as the lower bound and the dry-spell threshold increased.

The greater efficiency in the use of information in the PDS approach was reflected in the lower dispersion of the points in the L-moments ratios diagram. In comparison with PDS clouds, AMS showed a higher dispersion.

In addition, it was clear that a three-parameter distribution (GP) adapted better to the data series than a two-parameter distribution (Gumbel), as it was more flexible. This can be clearly seen in the figures, in which the GP distribution appears as a line, whereas the Gumbel is shown as a single point. The GP distribution proved to be a good model for the PDS series, as demonstrated by the closeness of the distribution line to the individual series, whereas the AMS cloud showed a higher dispersion with respect to the point representing the Gumbel distribution.

As mentioned earlier, the main problem in using PDS involves the selection of the lower bound. In theory, the method is invariant to the variation in the lower bound. In practice, however, the results may vary greatly, especially with the sample sizes that are common in hydro-climatic studies. This is exemplified in Figure 6, in which the maximum dry spells expected in 50 years are shown for six weather stations, in relation to the lower bound used. Whereas this value was expected to be similar independently of the lower bound chosen, it showed great random variation, as high as $20 \%$ in some cases. In this paper we assumed that the average of the different values would provide a good estimate of the unknown true value, being less uncertain than using a unique, arbitrary, threshold. 


\section{2- Comparison of maximum dry spell estimations using the AMS/G and PDS/GP approaches with the observed maximum dry spells}

Figures 7 and 8 compare AMS/G and PDS/GP estimates with the observed maximum dry spells for the 0.1 and $5 \mathrm{~mm}$ series. The AMS/G method clearly underestimated the duration of the observed maximum dry spells. The underestimation was greater than 30 days for the $5 \mathrm{~mm}$ dry-spell series, which severely limits the practical use of this method. The PDS/GP performed much more accurately for both the 0.1 and $5 \mathrm{~mm}$ dry-spell series.

The RMSE between the observed and estimated values is also highly indicative of the better performance of the PDS/GP distribution. There was a better adjustment for the 0.1 mm series $(\mathrm{RMSE}=9.8 \mathrm{v} .17 .3)$, while for the $5 \mathrm{~mm}$ dry-spell series, the adjustment was also better (RMSE $=19.8$ v. 27.2).

Figure 9 shows the spatial distribution of the maximum dry spells observed in the study area between 1951-2000, and the estimations using the PDS/GP and AMS/G approaches for the $0.1 \mathrm{~mm}$ dry-spell series. The longest dry spells are located in the eastern areas, with values over 130 consecutive days of precipitation over below $0.1 \mathrm{~mm}$. The same pattern is revealed by both estimations, but the Gumbel estimations are clearly lower than the observed figures. The PDS/GP map shows a much closer match to the observed data.

The spatial distribution and the estimations for the $5 \mathrm{~mm}$ dry-spell series are shown in Figure 10. The spatial patterns differ markedly from those in Figure 9. The most extreme dry spells (e.g. 170 days of precipitation below $5 \mathrm{~mm}$ ) were located in the centre of the study area. There were significant contrasts between the centre and depression borders, with differences of more than 50 days. The differences between modelled and observed values were again lower for the PDS/GP approach than for the AMS/G approach. 
The absolute errors of the estimations are shown in Figures 11 and 12. The high magnitude of the errors resulting from the AMS/G approach is evident. Here, the positive errors indicate the underestimation provided by this approach. By contrast, the errors of the PDS/GP approach include low positive and negative values and the estimation is, in general, better.

\section{4- DISCUSSION AND CONCLUSIONS}

Daily precipitation dry-spell series are commonly used in the stochastic analysis of drought occurrence. Extreme values correspond to long spells of consecutive days without precipitation that generate episodes of climatic drought. To date, the frequency analysis of these extreme values has been carried out using AMS adjusted to the Gumbel distribution (Lana and Burgueño, 1998b; Ascaso and Casals, 1981, Perzyna, 1994).

In this paper, we have used a PDS sampling in conjunction with a Generalized Pareto distribution, adopting a similar approach to that used in other studies that have sought to model extreme precipitations (Alila, 2000), floods (Mkhandi et al., 2000) or hydrological droughts (ARIDE, 2002). The results obtained have been compared to those obtained when adopting the AMS/G approach for the maximum dry spell series observed in the study area.

The use of PDS for the stochastic modelling of extremes has yielded good results in the analysis of hydrological variables (Moreno and Roldan, 1999; Alila, 2000; Mkhandi et al., 2000), whereas numerous studies have pointed out that AMS produces a significant loss of data for extreme modelling (Cunnane, 1973; Madsen et al., 1997a and b). In this paper, the greater efficiency of PDS has been demonstrated for dry-spell series by the lower 
dispersion of the points in the L-moments ratios diagram. In comparison with PDS clouds, AMS show a higher dispersion, yielding greater uncertainty.

Different probability distributions can be used to fit both AMS and PDS. The Gumbel distribution is a two-parameter extreme values distribution widely used in modelling AMS. It has been compared to the three-parameter Generalized Pareto distribution fitted to PDS. Generalized Pareto is the limit distribution for excesses over an upper limit, and is the most frequently used model with PDS (Kjeldsen et al., 2002; Madsen et al., 1997a and b). It is obvious that a three-parameter distribution would fit the observed data better than a twoparameter one. Nevertheless, the need to estimate a greater number of parameters introduces an extra source of uncertainty that can affect the final estimates.

In spite of this, the RMSE obtained by the PDS/GP is lower than that obtained by the AMS/G when analysing the empirical maximum dry spells for a 50-year time series. Moreover, in common with the findings reported in several studies (Neyman and Scott, 1971; Cowpertwait et al., 1996; Beguería, 2002), the AMS/G clearly underestimates the empirical extreme dry spells. For this reason, the PDS/GP approach is recommended for estimating drought risk for longer recurrence intervals, and which therefore exceed the longitude of the data set.

One shortcoming of the method proposed is the selection of the upper limit used to define the PDS. We found that the final quantile estimates vary significantly when only small changes are made in the upper limit used. To deal with this problem we propose the use of different upper limits when constructing a set of PDS, and then taking the average quantile estimates obtained with them. A set of PDS with limits ranging from 90 to 99.75 centiles rising by 0.25 steps was used in this paper. This proved to stabilize the variability of the 
quantile estimates. However, if this methodology is to used on a more general scale, the upper limit range used needs to be defined more accurately, as it can differ for each data set.

This paper has demonstrated that the widely used AMS/G approach underestimates the observed extreme dry-spell risk. By contrast, the PDS/GP approach produces more accurate estimates. The shortcomings of this methodology have been discussed, and a modified sampling method proposed. There are sufficient theoretical indications suggesting that this methodology can be exported to other regions. However, this needs to be confirmed by other studies.

The methodological improvement described here is of potential importance for agrarian planning, since it yields more precise estimations of extreme drought risks. The method should also be of benefit in crop management as it facilitates the drawing of risk maps and the drafting of preventive and palliative plans for the mitigation of the effects of drought.

\section{ACKNOWLEDGEMENTS}

This paper was supported by the following projects: "La sequía en Aragón: tendencias climáticas seculares y patrones de cambio ambiental" (CLI99-098), "Caracterización espacio-temporal de las sequías en el valle medio del Ebro e identificación de sus impactos" (BSO2002-02743), "Identificación de áreas fuente de sedimento y áreas generadoras de escorrentía en relación con los cambios de uso del suelo" (HIDROESCALA, REN2000-1709-C04-01/GLO) and "Procesos hidrológicos en áreas seminaturales mediterráneas" (PROHISEM, REN 2001-2268-C02-01/HID), financed by 
the CICYT. We wish to thank two anonymous reviewers for their valuable comments, and we also thank specially Mr. R. Rycroft for their linguistic revision.

\section{REFERENCES}

Alila Y. 2000. Regional rainfall depth-duration-frequency equations for Canada. Water Resources Research 36: 1767-1778.

Alyamani MS, Sen Z. 1997. Spatio-temporal dry and wet spell duration distributions in south-western Saudi Arabia. Theoretical and Applied Climatolog, 57: 165-179.

ARIDE. 2002. Assessment of the regional impact of droughts in Europe. European Community Framework Programme for Research and Technical Development Environment and Climate Work Programme. Final Report. http://www.hydrology.uni-freiburg.de/forsch/aride/

Ascaso A, Casals M. 1981. Periodos secos y sequías en la depresión central del Ebro. Geographicalia 11-12: 55-70.

Ashkar F, Rouselle J. 1987. Partial duration series modeling under the assumption of a poissonian flood count, Journal of Hydrology 90: 135-144.

Austin RB, Cantero-Martínez C, Arrúe JL, Playán E, Cano-Marcellán P. 1998. Yieldrainfall relationships in cereal cropping systems in the Ebro river valley of Spain. European Journal of Agronomy 8: 239-248.

Balairón L. 1997. El clima mediterráneo y sus características en el contexto de la circulación general atmosférica. In El paisaje mediterráneo a través del espacio y del tiempo. Implicaciones en la desertificación, Ibáñez JJ, Valero B, Machado C (eds.). Geoforma Ediciones, Logroño: 131-160.

Beguería S. 2002. Revisión de métodos paramétricos para la estimación de la probabilidad de ocurrencia de eventos extremos en Climatología e Hidrología: El uso de series de excedencias y su comparación con las series de máximos anuales. In La información climática como herramienta de gestión ambiental, Cuadrat JM, Vicente SM, Saz MA (eds.) University of Zaragoza: 83-92. 
Beguería S. 2003. Identificación y características de las fuentes de sedimento en áreas de montaña: erosión y transferencia de sedimento en la cuenca alta del río Aragón, $\mathrm{PhD}$ Thesis (unpublished), University of Zaragoza.

Berger A, Goosenes C. 1983. Persistence of wet and dry spells al Uccle (Belgium). Journal of Climatology 4: 21-34.

Bobee B, Rasmussen P. 1995. Recent advances in flood frequency analysis. U.S. National Report of IUGG, 1991-1994.

Bobee B, Cavadias G, Ashkar F, Bernier J, Rasmussen P. 1993. Towards a systematic approach to comparing distributions used in flood frequency analysis. Journal of Hydrology 142: 121-136.

Bruce JP. 1994. A perspective on reducing losses from natural hazards. Bulletin of the American Meteorological Society 75: 1237-1240.

Chang TJ, Kleopa XA. 1991. A proposed method for drought monitoring. Water Resources Bulletin 27: 275-281.

Chow VT. 1964. Handbook of Applied Hydrology. McGraw-Hill, New York, NY.

Chow VT, Maidment DR, Mays LW. 1988. Applied Hydrology. McGraw-Hill, New York, NY.

Cowpertwait PSP, O'Connell PE, Metcalfe AV, Mawdsley JA. 1996. Stochastic point process modelling of rainfall. I. Single-site fitting and validation. Journal of Hydrology 175: 17-46.

Creus J, Puigdefábregas J, García-Ruiz JM. 1978. Duración de períodos secos en el Alto Aragón. VII Coloquio de Geografia AGE: 53-60.

Creus J. 1983. El clima del alto Aragón occidental. Instituto de estudios Pirenaicos. Serie Monografías, 109. Jaca.

Creus J. 1996. Variaciones en la disponibilidad hídrica mensual en el valle del Ebro. In Clima y agua: la gestión de un recurso climático, Marzol MV, Dorta P, Valladares P (eds.). University of La Laguna: 79-86.

Creus J, Ferraz J. 1995. Irregularidad pluviométrica y continentalidad térmica en el valle medio del Ebro. Lucas Mallada 7: 147-164.

Cuadrat JM. 1991. La sequía en el valle del Ebro. Aspectos climáticos y consecuencias económicas. Revista de la Real Academia de Ciencias 85: 537-545. 
Cuadrat JM, Creus J, Vicente Serrano SM, Ferraz J. 2002. La sequía en Aragón a través de los registros históricos. In Aportaciones geográficas en memoria del prof. L. Miguel Yetano Ruiz. Peña JL and Longares LA (eds.): 123-130.

Cunnane C. 1973. A particular comparison of annual maxima and partial duration series methods of flood frequency prediction. Journal of Hydrology 18: 257-271.

Davy L. 1978. Lébre. Étude hydrologique. Atelier, University of Lille III.

De Arruda HV, Pinto HS. 1980. An alternative model for dry spell probability analysis. Monthly Weather Review 108: 823-825.

Douguedroit A. 1987. The variations of dry spells in Marseilles from 1865 to 1984. Journal of Climatology, 7: 541-551.

Douguedroit A. 1990. Specificite et variations de la secheresse le long du litoral mediterraneen francais. Revue de Géographie de Lyon 65: 123-128.

Dracup JA, Lee KS, Paulson EG. 1980. On the definition of droughts. Water Resources Research 16: 297-302.

Estrela MJ, Peñarrocha D, Millán M. 2000. Multi-annual drought episodes in the Mediterranean (Valencia region) from 1950-1996. A spatio-temporal analysis. International Journal of Climatology 20: 1599-1618.

Flannigan MD, Harrington JB. 1988. A study of the relation of meteorological variables to monthly provincial area burned by wildfire in Canada (1953-1980). Journal of Applied Meteorology 27: 441-452.

Gabriel KR, Neumann J. 1957. On a distribution of weather cycles by length. Quarterly Journal of Royal Meteorological Society 83: 375-380.

Galliani G, Filippini F. 1985. Climatic clusters in a small area. Journal of Climatology 5: 487-501.

Gibbs WJ. 1975. Drought, its definition, delineation and effects. In Drought: Lectures presented at the $26^{\text {th }}$ session of the WMO. Report $n^{\circ}$ 5. WMO. Geneve: 3-30.

Greenwood JA, Landwehr JM, Matalas NC, Wallis JR. 1979. Probability weighted moments: definition and relation to parameters of several distributions expressible in inverse form. Water Resources Research 15: 1049-1054.

Gumbel EJ. 1958. Statistics of Extremes. Columbia University Press, 375 pp. 
Gupta VK, Duckstein L. 1975. A stochastic analysis of extreme droughts. Water Resources Research 11: 221-228.

Harrington J, Flannigan M. 1993. A Model for the Frequency of Long Periods of Drought at Forested Stations in Canada. Journal of Applied Meteorology 32: 1708-1716.

Hayes M, Wilhite DA, Svoboda M, Vanyarkho O. 1999. Monitoring the 1996 drought using the Standardized Precipitation Index. Bulletin of the American Meteorological Society 80: 429-438.

Hershfield DM. 1973. On the probability of extreme rainfall events. Bulletin of the American Meteorological Society 54: 1013-1018.

Hershfield DM. 1981. Frequency of dry day sequences. Water Resources Bulletin 17: 317320.

Hosking JRM. 1990. L-Moments: Analysis and estimation of distributions using linear combinations of order statistics. Journal of Royal Statistical Society B 52: 105-124.

Kite GW. 1977. Frequency and risk analysis in Hydrology. Water Resources Publications, Fort Collins, CO.

Kjeldsen TR, Smithers JC, Schulze RE. 2002. Regional flood frequency analysis in the KwaZulu-Natal province, South Africa, using the index-flood method. Journal of Hydrology 255: 194-211.

Lana X, Burgueño A. 1998a. Daily dry-wet behaviour in Catalonia (NE Spain) from the viewpoint of Markov chains. International Journal of Climatology 18: 793-815.

Lana X, Burgueño A. 1998b. Spatial and temporal characterisation of annual extreme droughts in Catalonia (NE Spain). International Journal of Climatology 18: 93-110.

Lana X, Serra C, Burgueño A. 2001. Patterns of monthly rainfall shortage and excess in terms of the Standardized Precipitation Index for Catalonia (NE Spain). International Journal of Climatology 21: 1669-1691.

Madsen H, Pearson CP, Rosbjerg D. 1997a. Comparison of annual maximum series and partial duration methods for modelling extreme hydrologic events. 1. At-site modelling. Water Resources Research 33: 759-769.

Madsen H, Pearson CP, Rosbjerg D. 1997b. Comparison of annual maximum series and partial duration methods for modelling extreme hydrologic events. 2. Regional modelling. Water Resources Research 33: 771-790. 
Martín-Vide J, Conesa C, Moreno MC. 1992. Acerca de la bondad de las cadenas de Markov de primero, segundo y tercer órdenes en el análisis de las sequías del sureste de España. Actas del V Coloquio de Geografía cuantitativa, Zaragoza: 485500.

Martín-Vide J, Gómez L. 1999. Regionalisation of peninsular Spain based on the length of dry spells. International Journal of Climatology 19: 537-555.

McKee TBN, Doesken J, Kleist J. 1993. The relationship of drought frequency and duration to time scales. Eighth Conf. On Applied Climatology. Anaheim, CA, Amer. Meteor. Soc: 179-184.

McKee TBN, Doesken J, Kleist J. 1995. Drought monitoring with multiple time scales. Ninth. Conf. On Applied Climatology, Dallas, TX, Amer. Meteor. Soc: 233-236.

Mkhandi SH, Kachroo RK, Gunasekara TAG. 2000. Flood frequency analysis of southern Africa: II. Identification of regional distributions. Hydrological Sciences - Journal des Sciences Hydrologiques 45: 449-464.

Moreno F, Roldán J. 1999. Regional daily precipitation stochastic model parameters. Application to the Guadalquivir valley in southern Spain. Physics and Chemistry of the Earth (B) 24: 35-47.

Neyman J, Scott EL. 1971. Outlier proneness of phenomena and related distributions. In (J.S. Rustagi, Ed) Optimizing Methods in Statistics: 413-423.

Nobilis F. 1986. Dry spells in the alpine country Austria. Journal of Hydrology 88: 235251.

Obasi GOP. 1994. WMO's role in the international decade for natural disaster reduction. Bulletin of the American Meteorological Society 75: 1655-1661.

Palmer WC. 1965. Meteorological droughts. U.S. Department of Commerce Weather Bureau Research Paper 45, 58 pp.

Pérez Manrique C, Garmendia MI, Seco J, Garmendia J. 1984. Estudio de rachas secas y lluviosas en Gijón y San Sebastián. Revista de Geofísica 40: 73-80.

Perzyna G. 1994. Spatial and temporal characteristics of maximum dry spells in southern Norway. International Journal of Climatology 14: 895-909.

Rao AR, Hamed KH. 2000. Flood frequency analysis. CRC Press. 350 pp. 
Romero R, Guijarro JA, Ramis C, Alonso S. 1998. A 30-year (1964-1993) daily rainfall data base for the Spanish Mediterranean regions: first exploratory study. International Journal of Climatology 18: 541-560.

Sangoyomi TB, Harding BL. 1995. Mitigating impacts of a severe sustained drought on Colorado river water resources. Water Resources Bulletin 31: 925-938.

Sankarasubramanian A, Srinivasan K. 1999. Investigation and comparison of sampling properties of L-moments and conventional moments. Journal of Hydrology 218: 1334.

Saz MA, Creus J. 1998. Estudio dendroclimático de las rachas secas y húmedas en el sector central de la Depresión del Ebro. Geographicalia 36: 159-172.

Sivakumar MVK. 1992. Empirical analysis of dry spells for agricultural applications in West Africa. Journal of Climate 5: 532-539.

Thornthwaite CW. 1948. An approach toward a rational classification of climate. Geographical Review 38: 55-94.

Vogel RM, Fennessey NM. 1993. L-moment diagrams should replace product moment diagrams. Water Resources Research 29: 1745-1752.

Wilhite DA. 1991. Drought planning and State government: Current status. Bulletin of the American Meteorological Society 72: 1531-1536.

Wilhite DA. 1996. A methodology for drought preparedness. Natural Hazards 13: 229-252.

Wilhite DA, Glantz MH. 1985. Understanding the drought phenomenon: The role of definitions. Water International 10: 111-120.

Wilhite DA, Wood DA. 1985. Planning for drought: the role of state government. Water Resources Bulletin 21: 31-38.

Wilhite DA, Rosenberg NJ, Glantz MH. 1986. Improving Federal Response to Drought. Journal of Applied Meteorology 25: 332-342.

Willmott CJ. 1982. Some comments on the evaluation of model performance. Bulletin of the American Meteorological Society 63: 1309-1313.

WMO. 1989. Statistical distributions for flood frequency analysis. Operational Hydrology Report 33. WMO n 718. 


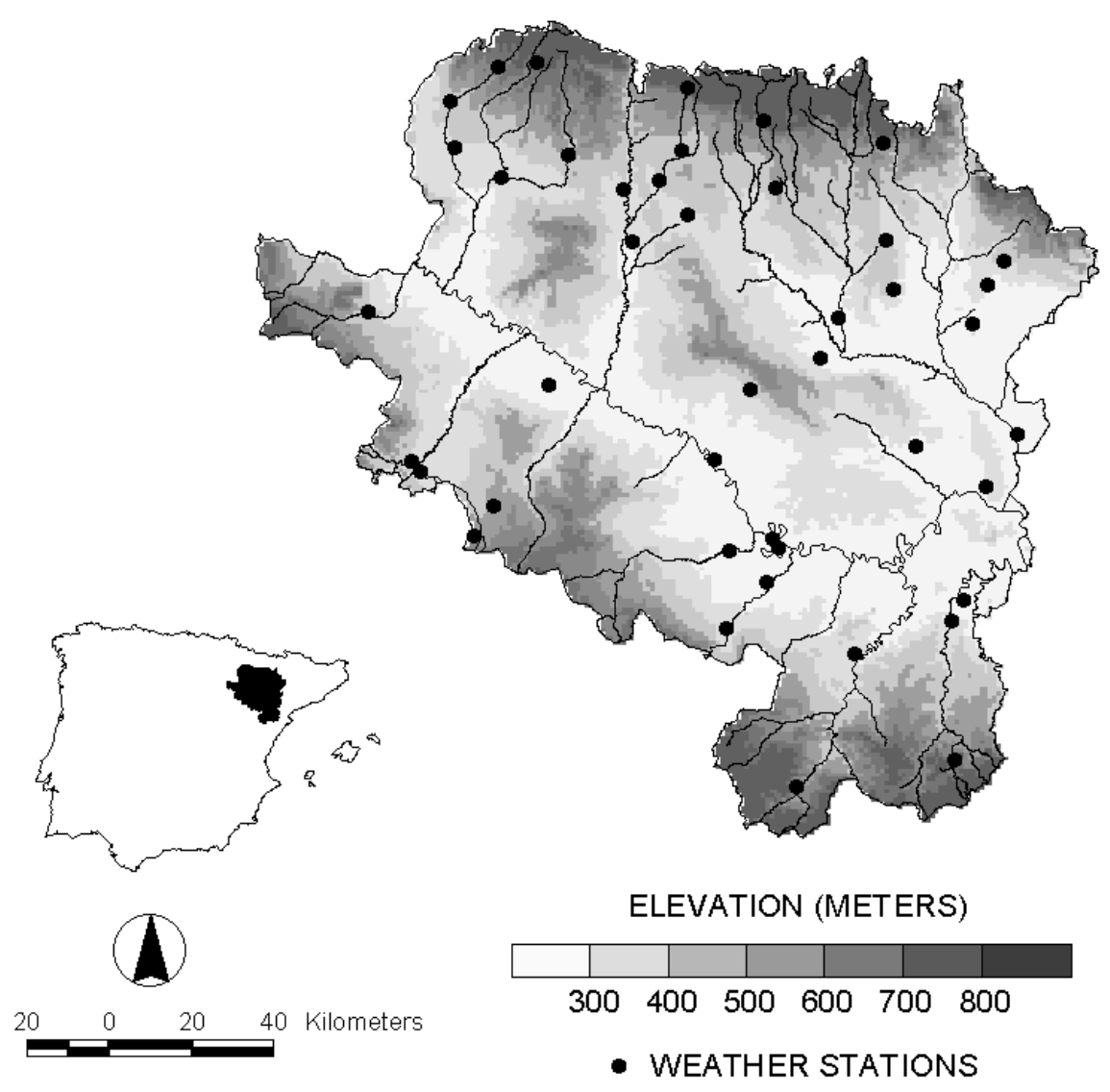

Figure 1: Study area 


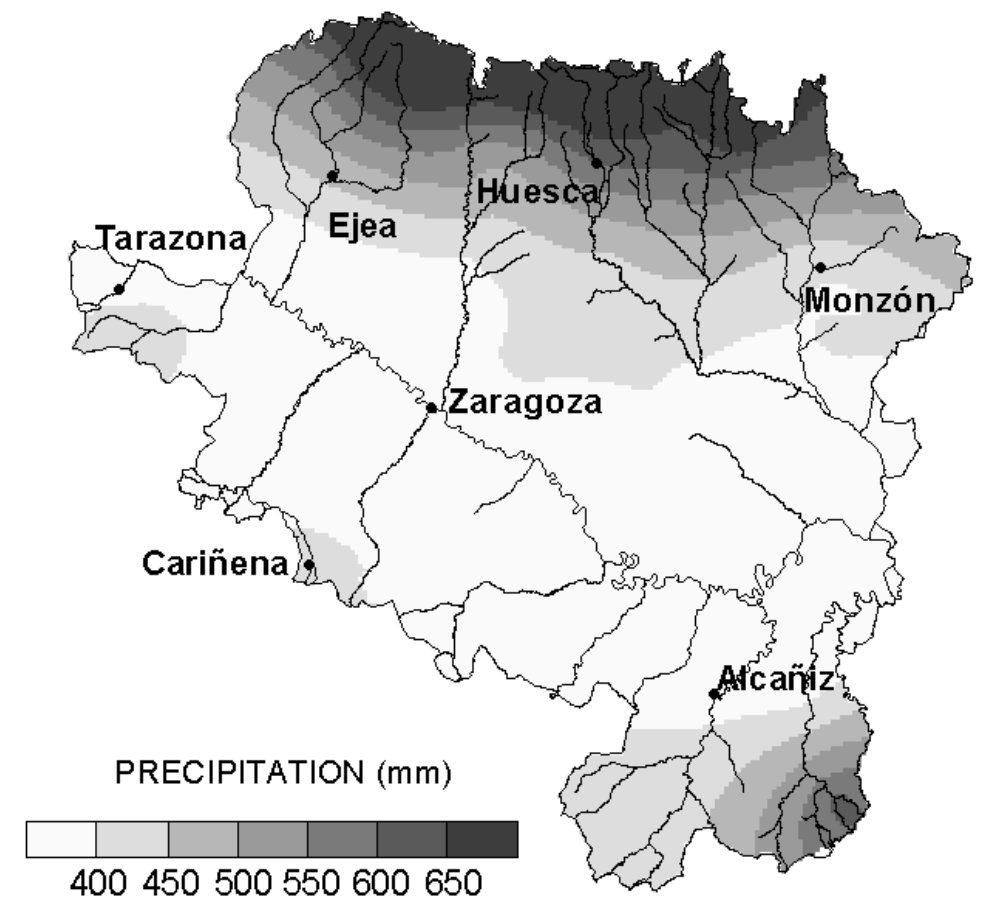

Figure 2: Annual mean precipitation 

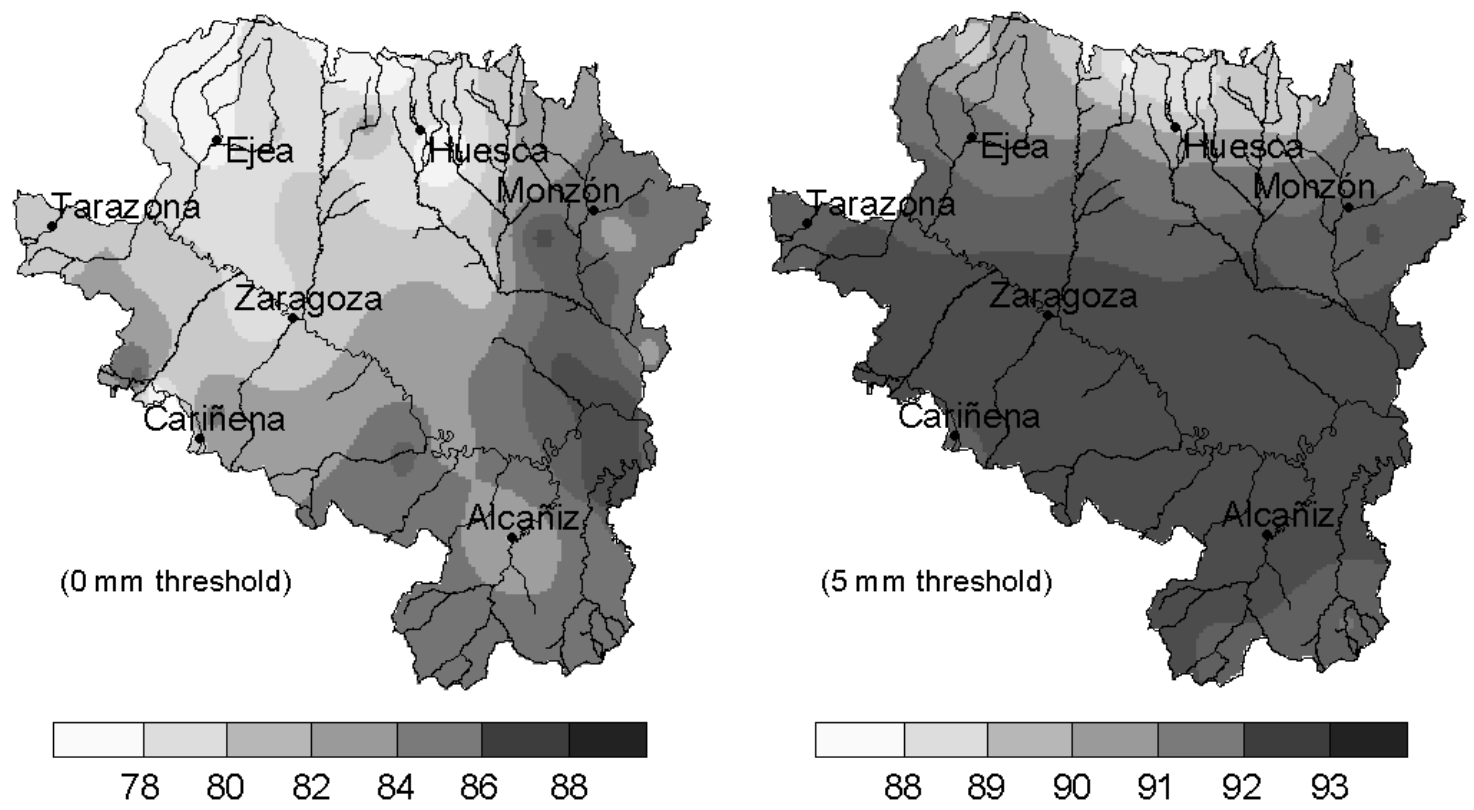

Figure 3: Percentage of dry days at 0.1 and $5 \mathrm{~mm}$ thresholds (1951-2000) 
Preprint of article published in International Journal of Climatology, 23:1103-1118 (2003)

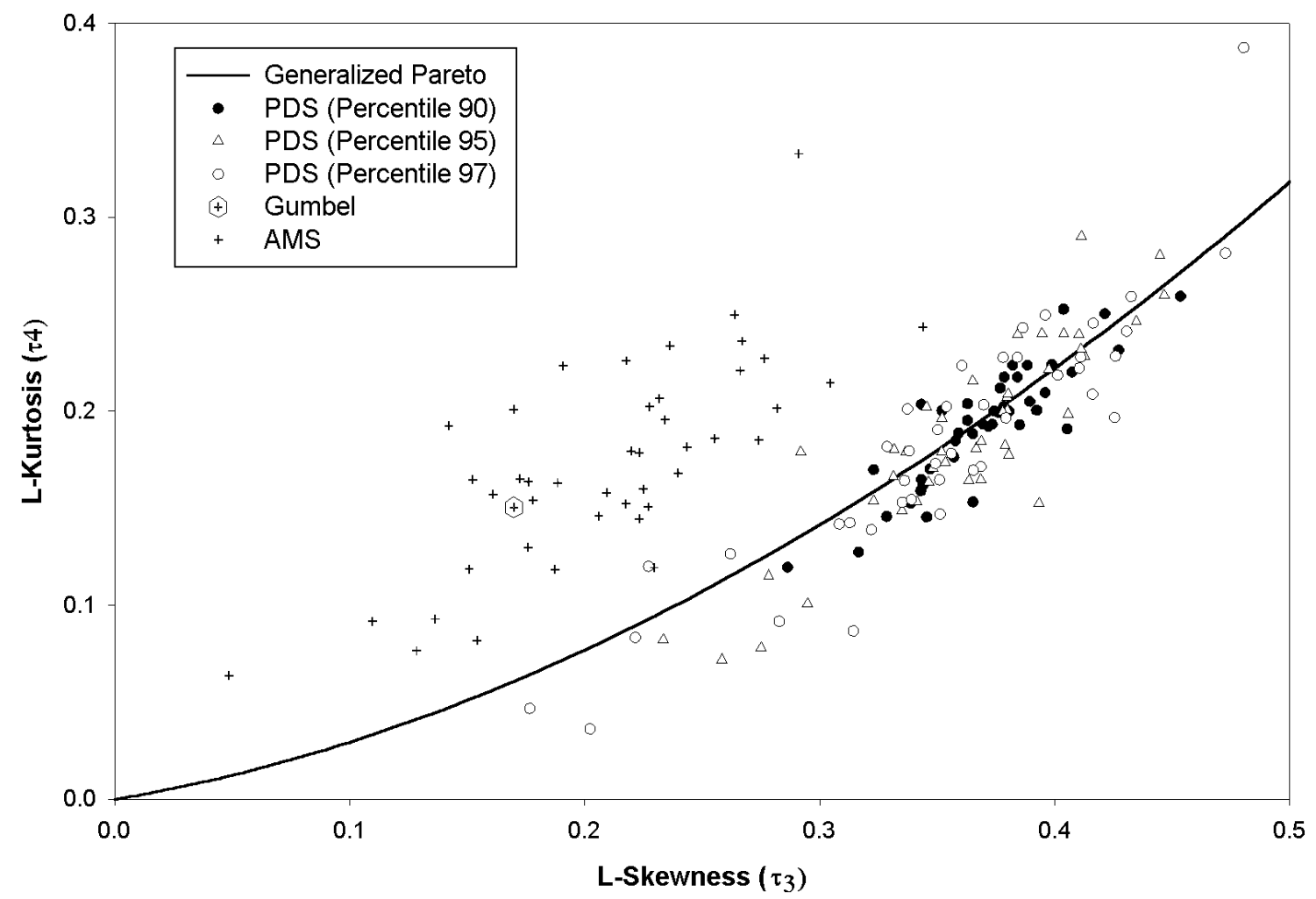

Figure 4: L-moments ratios diagram. Dry spell series at $0.1 \mathrm{~mm}$ threshold. The L-moments of AMS and PDS at three upper limit (defined by centiles 90, 95 and 97) are shown. 
Preprint of article published in International Journal of Climatology, 23:1103-1118 (2003)

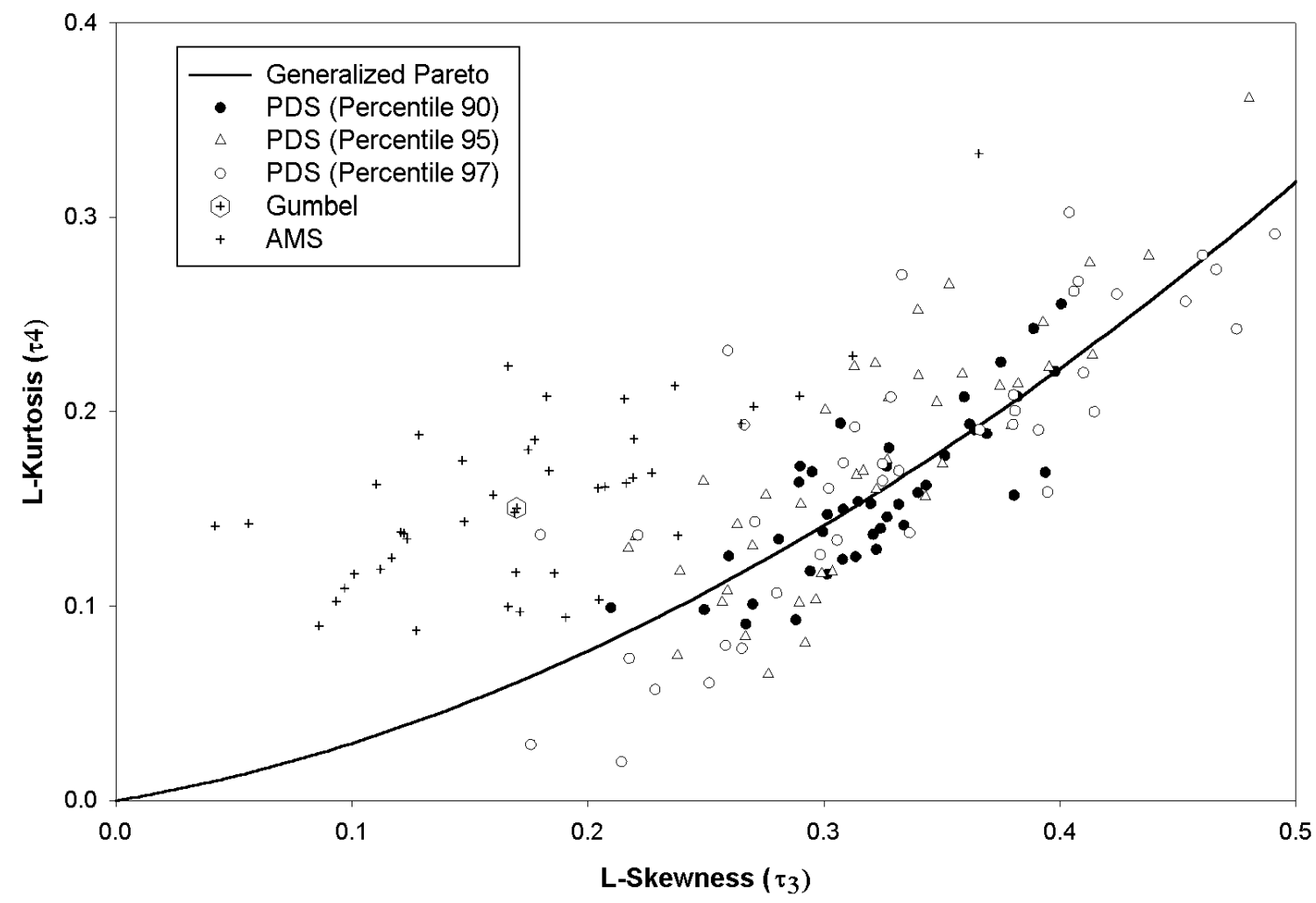

Figure 5: L-moments ratios diagram. Dry spell series at $0.1 \mathrm{~mm}$ threshold. The L-moments of AMS and PDS at three upper limit (defined by centiles 90, 95 and 97) are shown. 
Preprint of article published in International Journal of Climatology, 23:1103-1118 (2003)
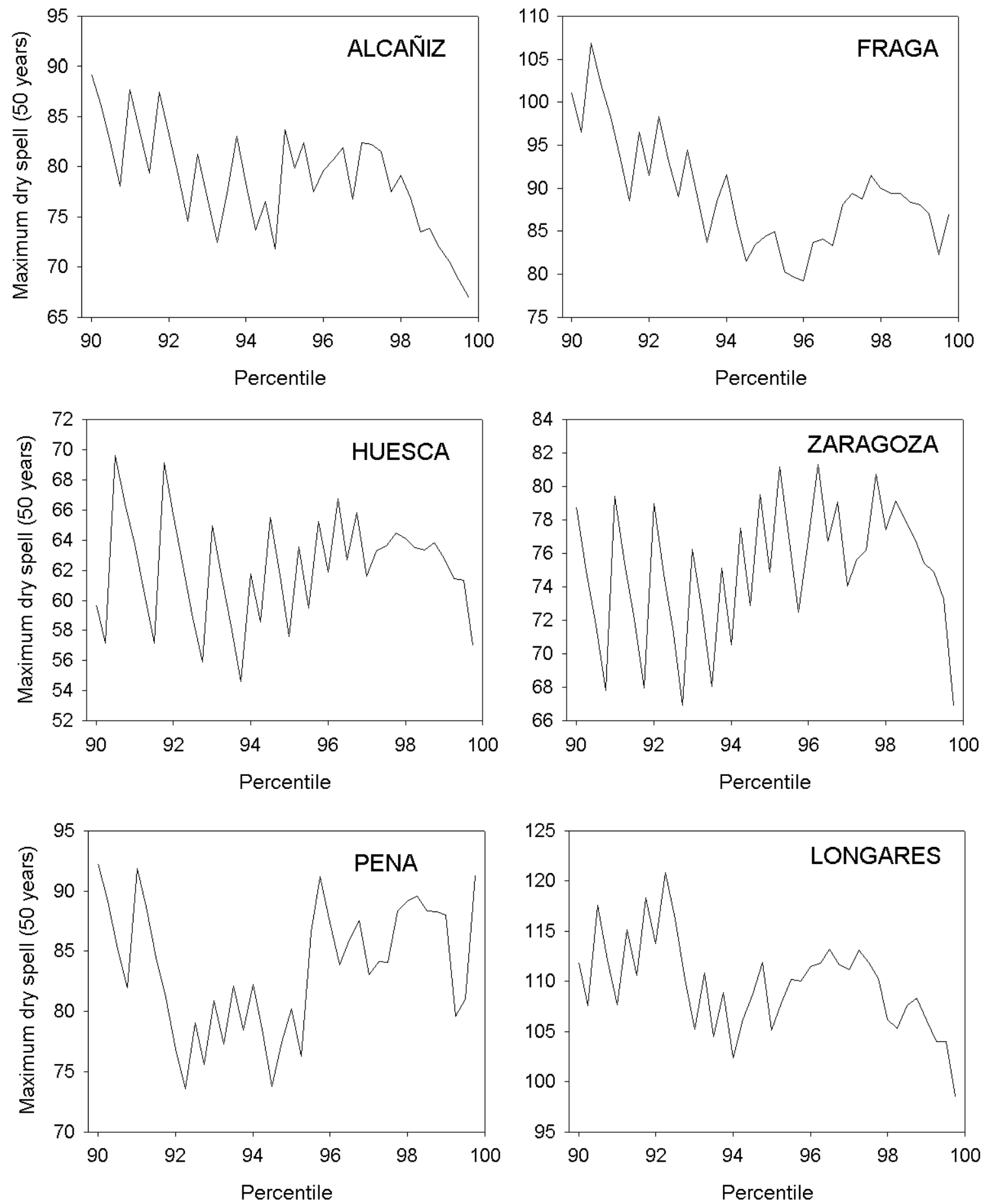

Figure 6: Oscillation of the maximum dry spell estimations in function of the selected percentile in the creation of the dry spell PDS. Six representative weather stations are shown. 


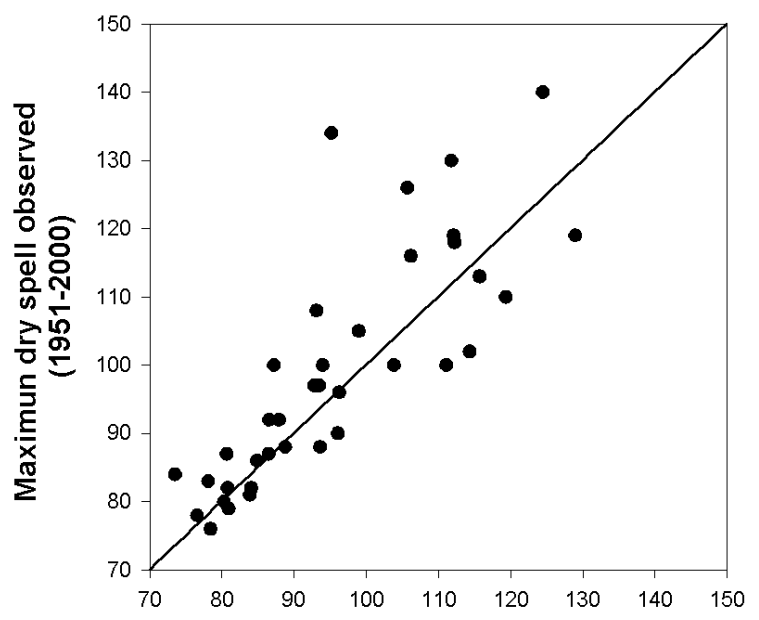

Maximum dry spells predicted by means of the Generalized Pareto distribution (dry-spell series of $0.1 \mathrm{~mm}$ )

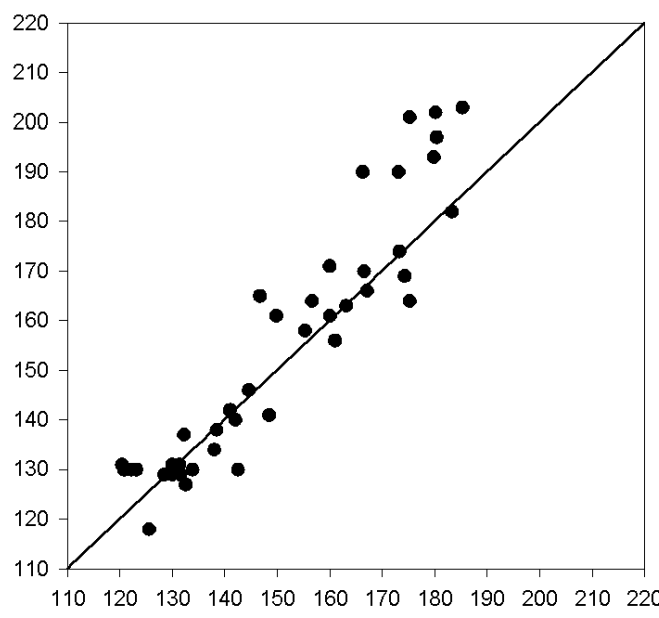

Maximum dry spells predicted by means of the Generalized Pareto distribution

(dry-spell series of $5 \mathrm{~mm}$ )

Figure 7: Differences between maximum dry spells observed and estimated using PDS modelled using the Generalized Pareto distribution. 


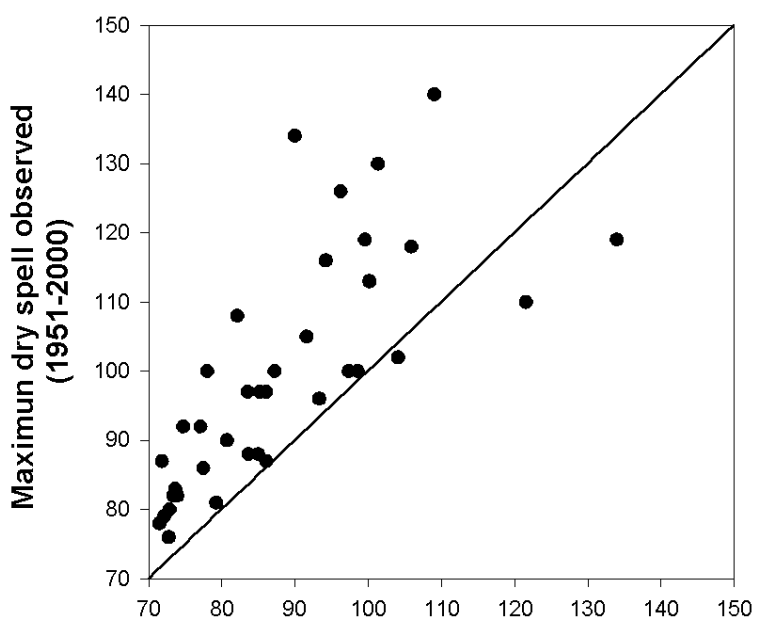

Maximum dry spells predicted by means of the Gumbel distribution (dry-spell series of $0.1 \mathrm{~mm}$ )

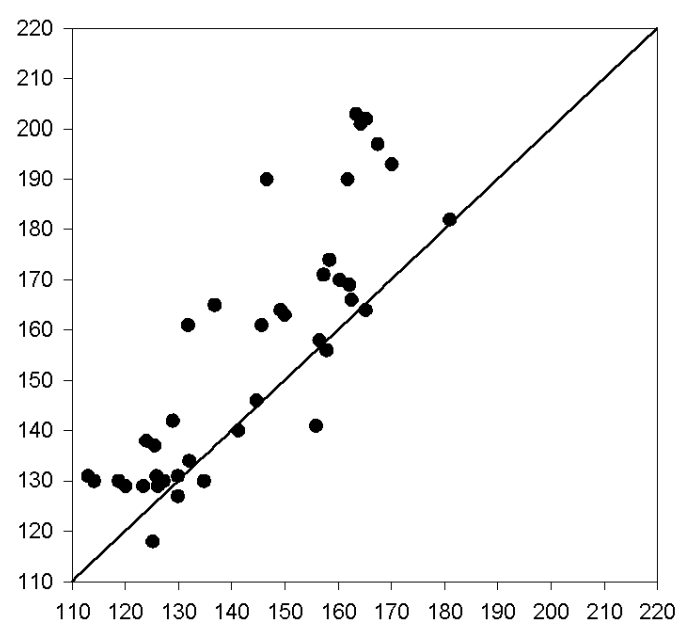

Maximum dry spells predicted by means of the Gumbel distribution (dry-spell series of $5 \mathrm{~mm}$ )

Figure 8: Differences between maximum dry spells observed and estimated using AMS modelled using Gumbel distribution. 

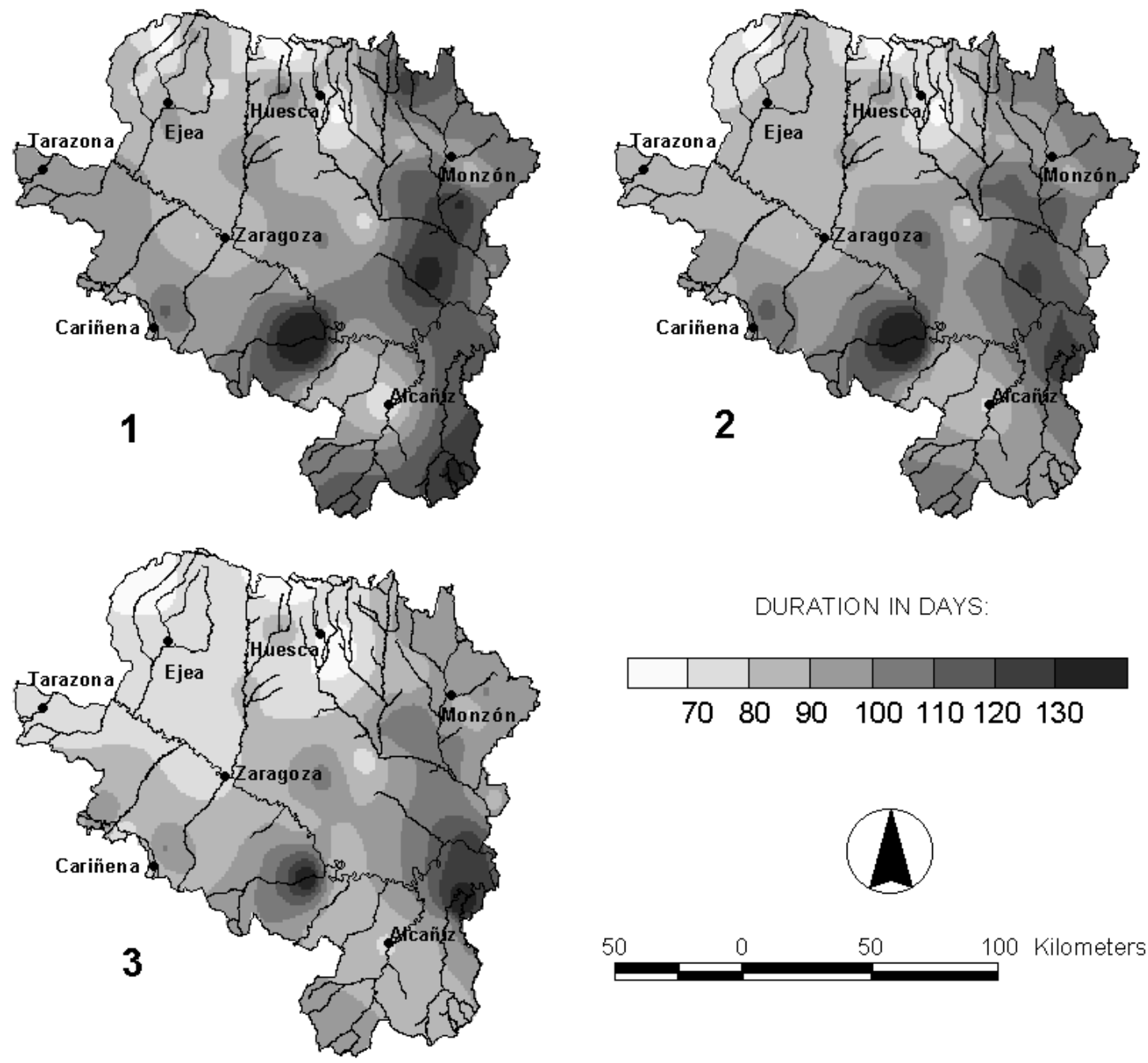

DURATION IN DAYS:
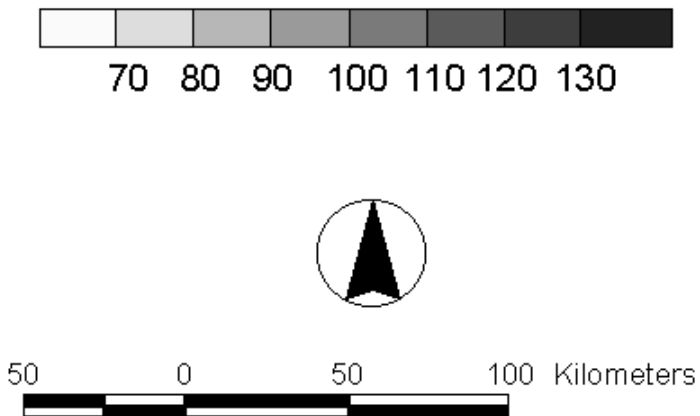

Figure 9: Dry spells at $0.1 \mathrm{~mm}$ threshold: 1 Observed maximum dry spells in 50 years (19512000). 2 Predicted maximum dry-spell using the Generalized Pareto distribution. 3. Predicted maximum dry-spell using Gumbel distribution. 

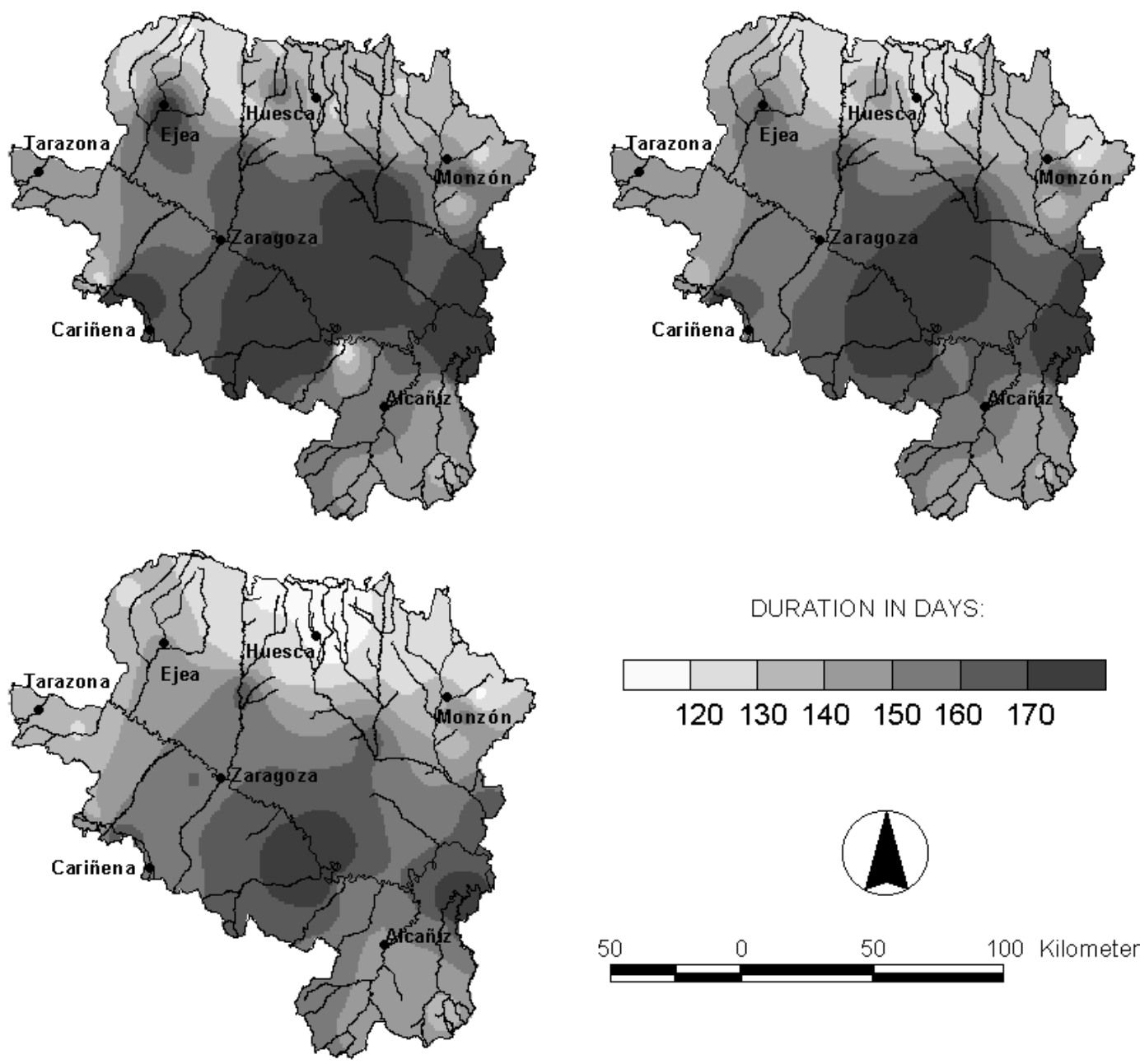

DURATION IN DAYS:
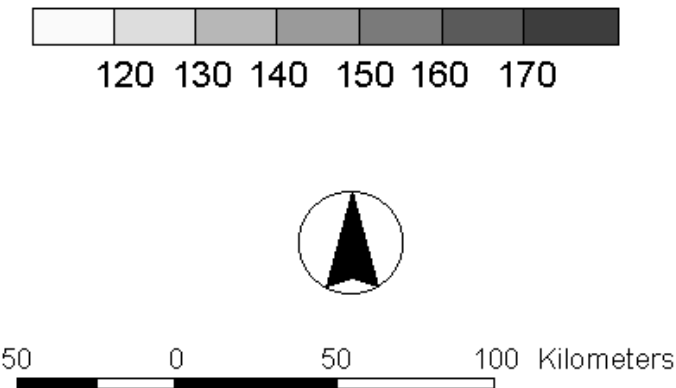

Figure 10: Dry spells at $5 \mathrm{~mm}$ threshold: 1 Observed maximum dry spells in 50 years (19512000). 2 Predicted maximum dry-spell using the Generalized Pareto distribution. 3. Predicted maximum dry-spell using Gumbel distribution. 

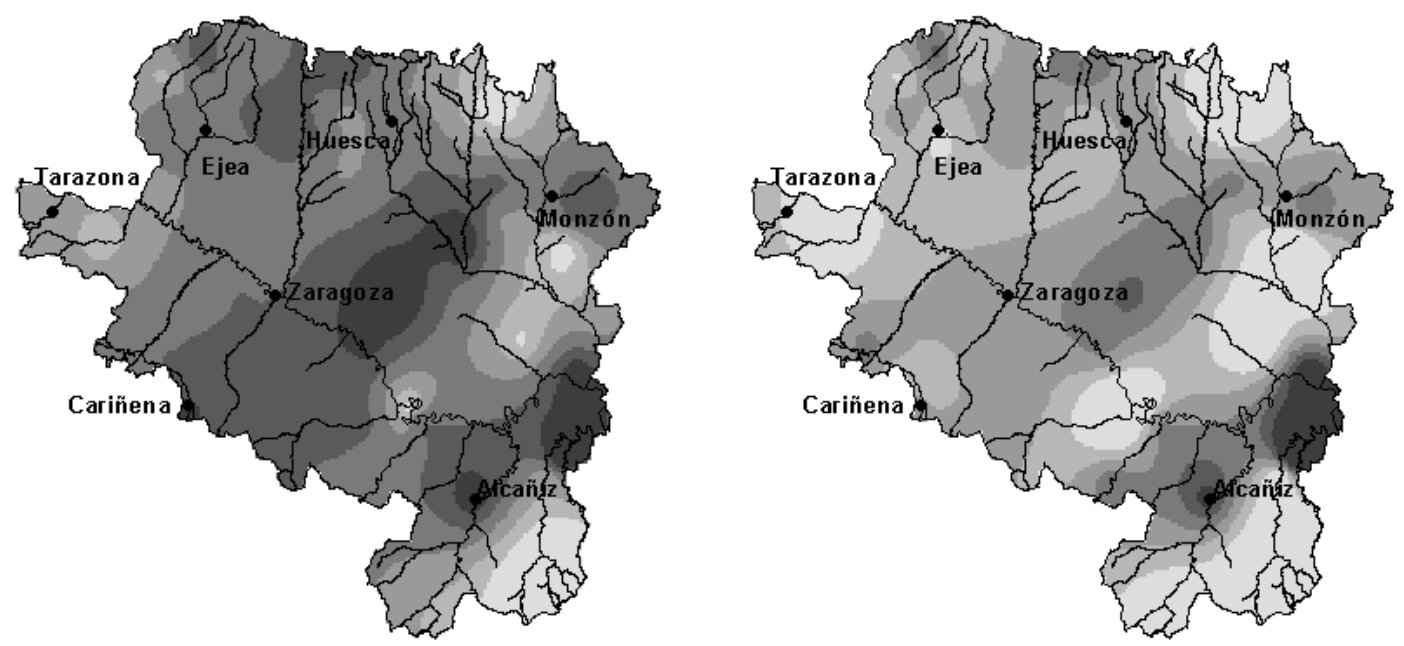

DIFERENCE IN DAYS:
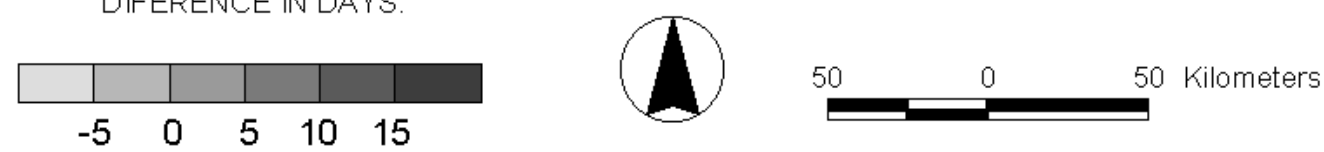

Figure 11: Differences between maximum dry spells observed and estimated at $0.1 \mathrm{~mm}$ threshold: 1- Observed-Estimated using Gumbel distribution. 2- Observed-Estimated using a Generalized Pareto distribution. 

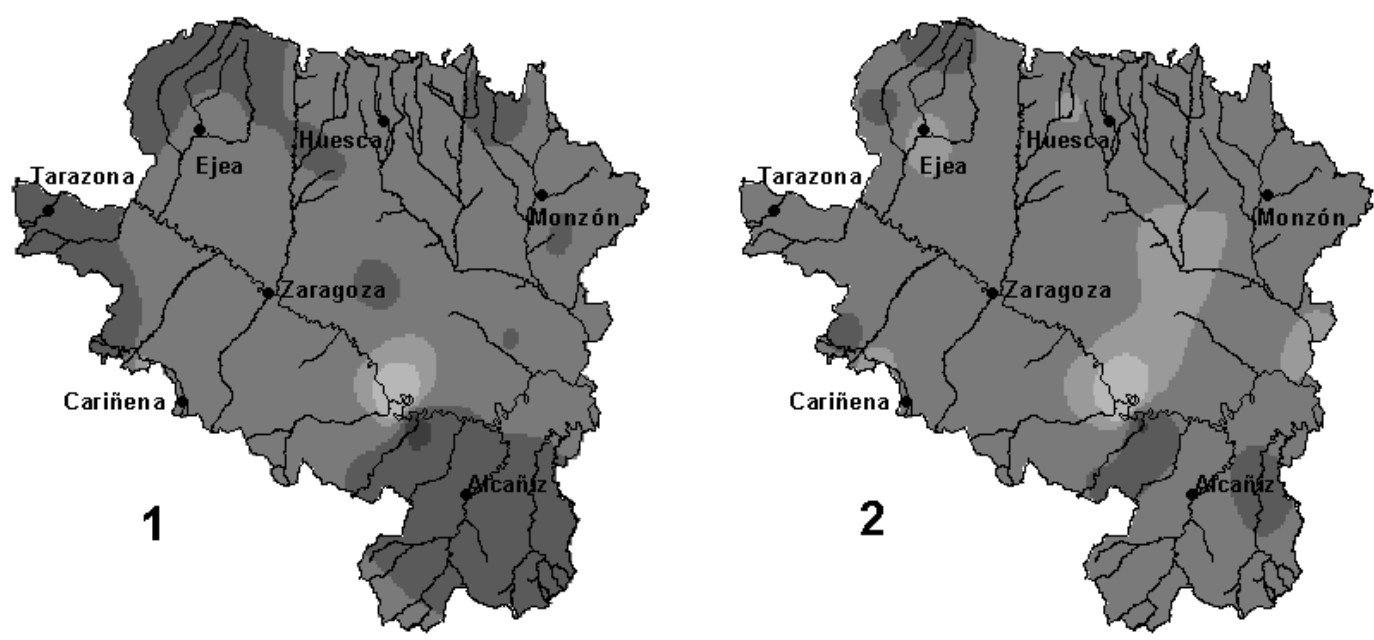

DIFERENCE IN DAYS:
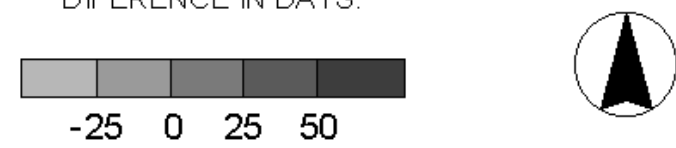

50 0 50 Kilometers

Figure 12: Differences between maximum dry spells observed and estimated at $5 \mathrm{~mm}$ threshold: 1- Observed-Estimated using Gumbel distribution. 2- Observed-Estimated using a Generalized Pareto distribution. 